\title{
A virada interpretativa na metodologia de pesquisa de Clifford Geertz e Quentin Skinner
}

\author{
The interpretive turn in the research methodology of \\ Glifford Geertz and Quentin Skinner
}

\section{Bruno Veçozzi Regasson ${ }^{\mathrm{a}} \odot$}

\begin{abstract}
Resumo De preocupação teórica e de tratamento metodológico bibliográfico, este trabalho busca debater a influência dos pressupostos da virada interpretativa das ciências sociais nos anos 1960 nos postulados metodológicos de Clifford Geertz e Quentin Skinner. A análise revela uma série de profundas afinidades: o combate aos discursos positivistas hegemônicos de seus períodos, o resgate das lições dos teóricos compreensivos do século XIX reformuladas pelas contribuições da filosofia da linguagem, o afastamento das radicalizações contra o ideal da ciência em relação a outros interpretativistas e, finalmente, a proposição de projetos intencionalistas, contextualistas e interpretativistas de análise de seus objetos. Esses projetos estão fundamentalmente sedimentados nas propostas metodológicas da descrição densa, para a antropologia, e do contextualismo linguístico, para a história das ideias.
\end{abstract}

Palavras-chave Virada interpretativa. Contextualismo linguístico. Descrição densa. História das ideias. Antropologia.

Abstract This paper, of theoretical and bibliographic methodological analysis, discusses the influence of interpretive premises in the social sciences during the 1960 s by investigating the methodological postulates of Clifford Geertz and Quentin Skinner. The analysis points to several affinities: a common dissent against the then hegemonic positivists discourses, the effort to revisit comprehensive theorists from the XIX century, by accepting more recent reformulations posed by the philosophy of the language, the refusal of radical stances that posit scientific ideals against other interpretivists, and the proposition of analytic lenses that encompass intentionalist, contextualist and interpretive preoccupations. These projects are fundamentally rooted in two methodological tools: for anthropology, that of thick description, and for the history of ideas, that of linguistic contextualism.

Keywords Interpretive turn. Thick description. Linguistic contextualism. History of ideas. Anthropology.

a Aluno de Doutorado pelo Programa de Pós-Graduação em Sociologia e Ciência Política da Universidade Federal de Santa Catarina. Mestre em Sociologia e Ciência Política pela mesma instituição. E-mail: brunovregasson@hotmail.com. 


\section{INTRODUÇÃO}

As ciências sociais (entendidas em seu conceito amplo como ciências da humanidade) sofreram nos anos 1960 e 1970 um forte abalo epistêmico em um contexto de construção de consensos e de amplos acordos metodológicos. Fortemente reativo ao positivismo, ao estrutural-funcionalismo e ao comportamentalismo das fileiras da academia, o movimento que se costumou chamar de virada interpretativa redesenhou os contornos e os enfoques da discussão sobre ciência de então - e os ecos desses argumentos ainda são sentidos em diversas áreas de estudo.

As reflexões propostas no período, por mais que multifacetadas e multidisciplinares, possuíam "importantes unidades de tema e abordagem" (Rabinow; Sullivan, 1979, p. 1, tradução própria) e influenciaram uma série de intelectuais: Charles Taylor (1931), Robert Bellah (1927-2013), Paul Ricouer (1913-2005), Theodor Adorno (1903-1969), Max Horkheimer (1895-1973), Jürgen Habermas (1929) e a Escola de Frankfurt como um todo são exemplos. Este breve artigo, porém, se propõe a analisar essa trajetória em três momentos: primeiramente, discutirá as unidades e referências comuns que constituem, em termos gerais, a virada interpretativa; em um segundo item, mostrará as consequências e o manuseio dessas disposições teóricas pelo antropólogo estadunidense Clifford Geertz (1926-2006), dando especial enfoque para o caráter interpretativo da descrição densa proposta por ele; em um terceiro, fará o mesmo, buscando iluminar a teoria do historiador britânico Quentin Skinner (1940-hoje), com os holofotes voltados para a interpretação como artefato metodológico no seu contextualismo linguístico. Nesse exercício, o artigo busca relevar profundas semelhanças - tanto em fundamento epistêmico quanto em prática de pesquisa - entre as abordagens dos dois intelectuais.

\section{A VIRADA INTERPRETATIVA}

Os argumentos da proposta interpretativa para as ciências sociais, desenvolvidos nas décadas de 1960 e 1970, respondem, antes de mais nada, a preocupações clássicas das teorias da compreensão nas ciências humanas. Enquanto formulações naturalistas mais associadas às correntes positivistas eram maturadas, nas últimas décadas do século XIX, teóricos já se voltavam a outras fontes para responder à apontada especificidade do objeto eleito pelas ciências sociais: a ação humana. Sua natureza significativa exigiria uma epistemologia distinta, que passou a ser buscada principalmente em tradições do idealismo alemão e da hermenêutica.

1 No original: "Important unities of theme and approach". 
O filósofo alemão Whilhelm Dilthey (1833-1911), por exemplo, postulava essa diferença ontológica entre objetos das ciências da natureza e das ciências humanas observando que a atividade do homem, naturalmente, possui uma dimensão psíquica interior absolutamente ausente nos fenômenos da natureza. Tal observação era o fundamento da diferenciação de metodologia da análise entre os campos: a explicação da natureza e a compreensão da história - a compreensão "do mundo físico que informa, motiva e constitui o fenômeno histórico e social”" (Gibbons, 2006, p. 564, tradução própria). O sociólogo Max Weber (1864-1920) continuaria e difundiria amplamente as reflexões sobre a dimensão autorreferenciada do mundo social. Em suas propostas metodológicas, fundava as bases da sociologia compreensiva, uma ciência: a) preocupada com a compreensão da ação social (todo o comportamento humano, referido a outrem, ao qual o indivíduo atuante confere significados subjetivos); b) idiográfica (focada em diferenciações, e não em generalizações); c) na qual a causalidade significa a demonstração concreta de relações entre ações específicas e suas motivações subjetivas. Não é exagero algum dizer, portanto, que "as questões ligadas à interpretação estão enraizadas nas Ciências Sociais” (Losso, 2011, p. 92).

A ligação direta com esses fundamentos da teoria social, porém, não é suficiente para compreender a virada dos anos 60, pois:

[A]pesar dos autores da virada interpretativa terem considerado as abordagens de cunho compreensivo [...] levaram-nas a um grau adiante, radicalizando o papel da interpretação - de método para condição de conhecimento - ao incorporar discussões que traziam novas dimensões para a questão, como as que se ocorreram no âmbito da virada linguística, na Fenomenologia e na Escola de Frankfurt (Coan, 2010, p. 14).

Foi principalmente a insatisfação com o mainstream positivista das ciências sociais que formou uma geração de críticos que, "com diversas vinculações disciplinares, protagonizaram um movimento (não planejado como atividade coletiva) de questionamento às bases sobre as quais eram alicerçadas as análises cientificistas do mundo social, constituindo um fenômeno nomeado posteriormente como virada interpretativa" (Losso, 2011, p. 93). Essa geração, mesmo muito diferente internamente, possui alguns movimentos teóricos chave para sua compreensão.

2 No original: "[of] the physic world that informs, motivates, and constitutes historical and social phenomena”. 
O primeiro nome dessa lista é o do filósofo austríaco Ludwig Wittgenstein (1889-1951), com destaque para seus últimos escritos - centralmente Investigações filosóficas (1953). Com Wittgenstein, a compreensão do significado de uma expressão deixou de ser uma figuração para se tornar seu uso prático na linguagem. Assim, "as palavras só adquirem significado no fluxo da vida" (Wittgenstein apud Costa, 2007, p. 38). A virada linguística dos pragmáticos trouxe a linguagem para um primeiro plano da investigação social. O sociólogo também austríaco Alfred Schütz (1899-1959), seguindo a discussão wittgensteiniana, apontou para o caráter sócio-histórico da linguagem, posto que toda comunicação eficiente se refere a um plano de fundo de conhecimento partilhado e construído pelos homens. Habermas e os frankfurtianos contribuíram, entre outros temas, apontando para a utilidade de tais reflexões para uma ciência humana conectada à vida cotidiana, às vidas e às experiências de pessoas reais no mundo real.

Os pilares da autoconfiança cientificista também foram severamente desafiados pela publicação de A estrutura das revoluções científicas (1962), do filósofo estadunidense Thomas Kuhn. Nele, Kuhn argumenta contra a pureza epistêmica das ciências - mesmo as naturais - e constata a influência que fatores externos exercem sobre o desenvolvimento do campo acadêmico. Os consensos científicos aparecem aqui como paradigmas contingenciais substituídos sucessivamente por razões estranhas à ciência. Embora recorrentes entre os autores da virada interpretativa, as consequências epistêmicas dessa observação variaram entre eles. Para alguns, chegou a significar o fim da crença na objetividade do conhecimento científico.

Tomemos por exemplo desse último pontoo canadense Charles Taylor (1931-hoje). Taylor foi um dos autores que esteve na linha de frente dentre os interpretativistas contra os "naturalistas" da ciência política hegemônica dos anos $60^{3}$. Para ele, o objeto das ciências sociais são ações socialmente constituídas, indissociáveis da linguagem que as descrevem e intersubjetivas; elas constituem uma generalidade de significados compartilhados, que por sua vez informam o significado das ações dos homens em um círculo hermenêutico. Dessa forma, "nós somos animais que se auto-interpretam e se auto-definem"4 (Rabinow; Sullivan, 1979, p. 6, tradução própria) em um sistema aberto, inseparável de interferências

3 Taylor estava criticando, majoritariamente, os seus contemporâneos comportamentalistas. Uma descrição rica e sociologicamente situada da "revolução behavorista" pode ser vista em: FARR, James. Remembering the revolution: behavioralism in american political science. In: FARR, James; DRYZEK, John; LEONARD, Stephen (org). Political science in history: research programs and political traditions. Cambridge, Cambridge University Press, 1995.

4 No original: "what we are is a self-interpreting and self-defining animal". 
externas e impassível de controle experimental e científico. Esta configura-se como a crítica à noção de cientistas isentos em busca de dados puros na realidade dura, substituída pela compreensão do mundo cultural como "o manejo de interpretações e interpretações de interpretações”5 (Rabinow; Sullivan, 1979, p. 6, tradução própria).

Em Taylor, fica clara a extensão da radicalização da geração dos anos 60:

(...) a argumentação dos interpretativistas da segunda metade do século XX defendia o caráter interpretativo do mundo social. Assim, a interpretação deixa de ser apenas uma forma de compreender a realidade, transformando-se também em um definidor ontológico do mundo e da ação humana no mundo (Losso, 2011, p. 95).

A linguagem dessa forma não é um espelho: o que vemos nela não é nosso reflexo, mas uma reinterpretação constante, "o jogo em que todos participamos" (Gadamer, 1967, p. 283). A virada interpretativa muda o foco das ciências para as concretas variedades de significados culturais, suas particularidades e complexidades. Postula a dependência do mundo social em existências anteriores de um "mundo partilhado de significados dentro do qual os sujeitos do discurso humano se constituem" " (Rabinow; Sullivan, 1979, p. 5, tradução própria) e aponta para esse fenômeno como uma realidade a ser apreendida pelo pesquisador para a compreensão da ação significativa do homem - uma afirmação profundamente contextualista, onde o contexto aparece como apreensível através da interpretação.

Como já apontado, essas linhas gerais de argumentação estarão certamente presentes nos autores interpretativistas do século XIX, mas em variados graus. Este texto tratará agora de entender a relação dos postulados aqui apresentados com a teoria antropológica de Clifford Geertz e a teoria da história das ideias de Quentin Skinner, com especial atenção às consequências para as propostas metodológicas dos autores.

\section{A DESCRIÇÃO DENSA DE CLIFFORD GEERTZ}

O nome de Clifford Geertz é um dos mais comumente associados ao approach interpretativo aqui abordado. Sua contribuição para o tema iniciou como uma proposta de rediscussão dos contornos da antropologia, mas logo se tornou uma

5 No original: "we are dealing with interpretations and interpretations of interpretations".

6 No original: "shared world of meaning within which the subjects of human discourse constitute themselves". 
consciente intervenção no campo geral das humanidades, constituindo-se como um sistemático esforço de repensar mesmo as mais básicas premissas das ciências sociais. Nesse sentido, Geertz sabia que não estava sozinho e aludia a um movimento maior, do qual se sentia parte:

[É uma verdade sobre as ciências sociais] que muitos cientistas têm virado as costas para o ideal explicativo de leis-e-instâncias em favor de um de casos-e-interpretações, procurando menos pelo tipo de coisa que conecta planetas e pêndulos e mais para o que conecta crisântemos e espadas. [...] Eu não apenas penso que essas coisas são verdade, eu penso que elas são verdade juntas; e a mudança cultural que as faz assim é o objeto desse ensaio: a reconfiguração do pensamento social.7 (Geertz, 1980, p. 165, tradução própria, grifos próprios)

Em termos gerais, o convite de Geertz era para que estudiosos das humanidades voltassem a sua atenção para significados e não comportamentos, buscassem compreender ao invés de postular leis causais, rejeitassem explicações mecânicas das ciências naturais em favor de explicações interpretativas, levassem a sério o empenho de reconstruir possibilidades de analogias e metáforas adequadas ao mundo social, considerassem a atividade humana como um texto e a ação simbólica como um drama (Shankman, 1984). Sua elaboração de como operacionalizar uma pesquisa antropológica fundada nesses pressupostos está em seu conceito de descrição densa ${ }^{8}$.

O começo da fundamentação de sua metodologia de análise passa por uma revisão e uma delimitação do seu objeto de análise: a cultura. Naquela que provavelmente é a passagem mais famosa de seu texto seminal Por uma teoria interpretativa da cultura (1973), Geertz propõe que seu conceito de cultura é essencialmente semiótico: "acreditando, como Max Weber, que o homem é um animal amarrado a teias de significados que ele mesmo teceu, assumo a cultura

7 No original: "[It is a truth about the social sciences] that many social scientists have turnedaway from a laws-and-instances ideal of explanation toward a cases-and-interpretations one,looking less for the sort of thing that connects planets and pendulums and more for the sort that connects chrysanthemums and swords. [...] I not only think these things are true, I think they are true together; and the culture shift that makes them so is the subject of this essay: the refiguration of social thought."

8 De acordo com Michael Martin, "Geertz é talvez o único conhecido intelectual a ter utilizado essa abordagem na prática da ciência social. Portanto, enquanto escritos de outros entusiastas proveram uma racionalidade filosófica, os trabalhos teóricos de Geertz, junto de seu trabalho de campo antropológico, forneceram tanto uma racionalidade quanto um modelo concreto de como os resultados de uma abordagem interpretativa se pareceriam" (Martin, 2013, p. 269, tradução própria). 
como sendo essas teias" (Geertz, 2008, p. 4, grifo próprio). Esse giro ontológico gera resultados amplos para a antropologia: a cultura deixa de envolver diretamente comportamento ou ação e passa a ser um fenômeno simbólico. Acessar esse objeto torna-se uma busca por significado: sua análise não é uma "ciência experimental em busca de leis", mas "uma ciência interpretativa" (Geertz, 2008, p. 4). A explicação "passa a ser entendida como um modo de conectar ação ao seu sentido ao invés de comportamento a seus determinantes9" (Geertz, 1980, p. 178, tradução própria).

Um fato inerente a essa concepção é que a cultura é publicamente apreensível, pois é partilhada entre os homens como um background ao qual eles se referem e recorrem sempre que dão significado a suas ações. Se não fosse pública, a comunicação seria em si impossível, compreender o outro seria tarefa infrutífera. Ainda, embora seja um fenômeno não material - uma ideação -, a cultura não existe na cabeça de alguém, pois ninguém a detém por completo; ela está em todos, em diferentes graus, mas existe como entidade independente de suas manifestações individuais.

É justamente por isso que, através do ferramental adequado, ela é acessível ao pesquisador atento. $\mathrm{O}$ conhecimento antropológico não vem de uma extraordinária sensibilidade ou alguma capacidade preternatural de pensar, sentir e perceber como um nativo, mas da busca e da análise de "formas simbólicas - palavras, imagens, instituições, comportamentos - nos termos a partir dos quais, em cada lugar, pessoas representam a si mesmas e entre si”'(Geertz, 1976, p. 228, tradução própria). Essa busca deve ser a empreitada básica da etnografia: a elaboração de uma descrição densa.

A descrição densa é um esforço de registro e descrição extensamente detalhados de uma sociedade (ou melhor: uma manifestação específica dela) observada, bem como de análise em termos de estruturas de significação, fundamento social e importância simbólica. Esse trabalho é multifocal: envolve "entrevistar informantes, observar rituais, deduzir os termos de parentesco, traçar as linhas de propriedade, fazer o censo doméstico, escrever seu diário” (Geertz, 2008, p. 7), assim como envolve, também, "observação participante e notas de campo, [...] história oral, gravações de áudio e/ou vídeo"11 (Leeds-Hurwitz, 2015, p. 2, tradução

9 No original: "comes to be regarded as a matter of connecting action to its sense rather than behavior to its determinants".

10 No original: "symbolic forms - words, images, institutions, behaviors - in terms of which, in each place, people actually present themselves and to one another".

11 No original: "participant observation and field notes, [...] oral histories, audio and/or video recordings". 
própria). Trata-se de apreender "uma multiplicidade de estruturas conceptuais complexas, muitas delas sobrepostas ou amarradas umas às outras, que são simultaneamente estranhas, irregulares e inexplícitas" (Geertz, 2008, p. 7) e, então, apresentá-las sistematicamente de modo a iluminar a teia de significados na qual está mergulhado aquele fenômeno que se busca compreender. Se "as ações sociais são comentários a respeito de mais do que elas mesmas" (Geertz, 2008, p. 17), então, a observação cuidadosa e detalhada dessas ações é um modo de capturar a teia de significados a qual elas se referem. É no fluxo de comportamento que as formas culturais encontram articulação, enquanto seu significado "emerge do papel que desempenham (Wittgenstein diria seu 'uso') no padrão de vida decorrente, não de quaisquer relações intrínsecas que mantenham umas com as outras." (Geertz, 2008, p. 12, grifo próprio). ${ }^{12}$

Disso resultam duas importantes considerações sobre o tipo de fazer científico da antropologia. A primeira delas é que a descrição etnográfica é microscópica. A preocupação central está nos detalhes culturais e no objeto em suas especificidades. Isso não quer dizer um conhecimento sem implicações generalizantes, mas que "o antropólogo aborda caracteristicamente tais interpretações mais amplas e análises mais abstratas a partir de um conhecimento muito extensivo de assuntos extremamente pequenos" (Geertz, 2008, p. 15). O sujeito específico da pesquisa é um objeto amplo, um modo de acessar a cultura, e não um modelo de microcosmo (uma versão em miniatura de uma sociedade). Mas a teoria aqui está necessariamente mais perto do caso específico do que a maioria das ciências: isso porque o ponto central do approaché acessar um mundo conceitual de sujeitos que habitam um mundo próprio; "não é codificar regularidades abstratas, mas tornar possíveis descrições minuciosas, não generalizar através dos casos, mas generalizar dentro deles" (Geertz, 2008, p. 18). O resultado, "e Geertz reconhece isso, é que explicação e descrição, distintas na ciência convencional, se tornam quase indistinguíveis" ${ }_{13}$ (Shankman, 1984, p. 263, tradução própria).

Outra contribuição de Geertz está contida nos pressupostos de sua metodologia, e é, ao mesmo tempo, a marca mais forte de sua teoria interpretativa da cultura e seu ponto mais polêmico. "Resumindo, os textos antropológicos são eles mesmos interpretações e, na verdade, de segunda e terceira mão. (Por definição, somente um "nativo" faz a interpretação em primeira mão: é a sua cultura)" (Geertz,

12 O exemplo clássico de Geertz é o da piscadela: se são movimentos fisicamente idênticos, seus usos em seus contextos o tornam atos de significados completamente diferentes (Geertz, 2008).

13 No original: "and Geertz appreciates it, is that explanation and description, distinct in conventional science, become almost indistinguishable”. 
2008, p. 11). Essa concepção implica em um problema básico de verificação e de acumulação de conhecimento: o que garante uma interpretação como superior a outra? De que forma um estudo antropológico avança o campo e auxilia os próximos pesquisadores?

As respostas do estadunidense são pouco práticas e amplamente questionadas. Segundo ele, interpretações são melhores que outras se são mais incisivas (Geertz, 2008) e se levam a pesquisa ao coração da questão (Geertz, 1973), parâmetros esses medidos pela densidade e coerência (camadas de inferência coerentemente interrelacionadas entre si) das descrições interpretativas. Em suas palavras, "não precisamos medir a irrefutabilidade de nossas explicações contra um corpo de documentação não-interpretada, descrições radicalmente superficiais, mas contra o poder da imaginação científica que nos leva ao contato com as vidas dos estranhos" (Geertz, 2008, p. 12). Mesmo que pouco acumulativo, o conhecimento antropológico possui sucessão e progresso, pois

fatos anteriormente descobertos são mobilizados, conceitos anteriormente desenvolvidos são usados, hipóteses formuladas anteriormente são testadas, entretanto o movimento não parte de teoremas já comprovados para outros recém provados, ele parte de tateio desajeitado pela compreensão mais elementar para uma alegação comprovada de que alguém a alcançou e a superou. (Geertz, 2008, p. 18)

Se essas preocupações estão presentes em Geertz, isso se deve ao fato de que, ao contrário de muitos outros interpretativistas dos anos 60 e 70, o antropólogo em nenhum momento abandonou o projeto do fazer científico enquanto tal e dizia-se nada tímido, "em absoluto" (Geertz, 2008, p. 17), ao afirmar o campo de estudo como ciência. Se há uma tensão entre subjetivismo e objetivismo nas suas reflexões, ele busca resolvê-la através de uma ciência interpretativa, de um treinamento de análises em realidades sociais e necessidades de pesquisa (Geertz, 1973) - um projeto que não apenas se afirmava científico, mas cientificamente superior às ciências sociais convencionais (Shankman, 1984).

\section{O CONTEXTUALISMO LINGUÍSTICO DE QUENTIN SKINNER}

As semelhanças entre os pressupostos de pesquisa de Clifford Geertz e Quentin Skinner são tantas que este artigo corre o risco de tornar-se repetitivo ao expor o contextualismo linguístico de Skinner em sequência à abordagem da descrição 
densa de Geertz. Ainda assim - ou melhor, precisamente por isso -, trata-se de um exercício de indubitável pertinência. Senão, vejamos.

Em termos gerais, Skinner e a Escola de Cambridge interessavam-se ao propor seu esqueleto metodológico em se opor tanto dos recortes sociologizantes quanto textualistas da sua área de estudo, a história das ideias. É esse tom (oposicionista) do mais famoso e polêmico artigo do britânico, Meaning and understanding in the history of ideias14(1969). Nele, as críticas direcionadas aos textualistas como Leo Strauss são um forte apelo à reconsideração do contexto de produção na interpretação de textos, bem como um chamado à compreensão desses como resultantes da agência de um ser intencionado. Aos contextualistas sociologizantes, o teor central do argumento é atacar a concepção positivista de busca por nexos causais entre contexto e texto como se fossem suficientes para esgotar a compreensão do pensamento de um autor. A episteme que fundamenta esses ataques e seu próprio conteúdo tem links diretos com a virada interpretativa.

Primeiramente, Skinner, ainda mais que Geertz, manuseou e sofreu fortíssimas influências da linguística pragmática. A concepção pragmática da linguagem ordinária, em que o significado "se dá no mundo como uma atividade" e "nada mais é do que uma técnica em que somos treinados" (Coan, 2013, p. 26), informa um conceito chave para Skinner: o de jogos de linguagem ${ }^{15}$. Entendidos como a dinâmica constante entre a linguagem e as atividades humanas cotidianas entrelaçadas à linguagem, são campo fértil para o empenho analítico da conexão entre expressões e contextos de uso, de modo a possibilitar a construção de um léxico de usos convencionais para suas regras e convenções. O conceito teve significativa importância nos seus enfrentamentos contra os textualistas, as "ideias-unidade" e as "ideias perenes", na sua concepção da busca por apreensão do significado de textos históricos e na própria solidificação dessa noção de significado(meaning).

Outra tese da linguística, de John Austin, tornou-se peça central no quebra-cabeça do contextualismo linguístico: a dimensão ilocucionária dos atos de

14 Ciente das mudanças de perspectivas do próprio autor durante sua carreira (que segue ativa), se limitam as pretensões aqui postas apenas ao estudo do original de 1969, abrindo a oportunidade para a análise da articulação da relação de Skinner com os interpretativistas nas suas posteriores revisões em outros estudos - em boa parte uma relação impossível de ignorar no estudo de suas reações aos seus críticos.

15 Citado nominalmente por Skinner em 69, o conceito de language games aparece como a ideia de que "nós somente podemos estudar uma ideia observando a natureza de todas as ocasiões e atividades [..] em que ela pode aparecer" (Skinner, 1969, p. 36, tradução própria).No original: "we can only study an idea by seeing the nature of all the occasions and activities [...] within which it might appear". 
fala, "relativa ao que o agente está fazendo ao dizer (in saying) algo" (Silva, 2010, p. 307). Nessa tese, a força do enunciado está na intenção do seu autor ao fazer o que estava fazendo. Essa formulação está vívida no conteúdo do Meaning and Understanding de $1969^{16}$.

Outra peça importante para a sustentação filosófica de Skinner é o historiador britânico R. G. Collingwood (1889-1943) e sua busca pela recuperação de uma tradição intencionalista na história. Para o autor, tudo o que entendemos por ação e evento na história pressupõe um agente e, consequentemente, um ser dotado de pensamento e intenção. $\mathrm{O}$ acontecimento, desse modo, possui uma exterioridade historiograficamente significativa e uma interioridade cuja busca é a verdadeira missão do historiador. Redescobrir a historicidade das ações humanas é "introduzir-se na cabeça dos autores do passado e olhar para as suas circunstâncias singulares" (Lopes, 2011, p. 181) e descobrir "[a] intencionalidade e [o] propósito as ações subjacentes ao processo histórico" (Coan, 2013, p. 61) que são necessariamente específicos, contingenciais, contextuais, o que, por fim, significa dizer que, para a história da teoria política, ela "não pode ser considerada como a história de diferentes respostas dadas a apenas um conjunto de questões, e sim como a história de problemas em constante mudança, cujas soluções mudavam com eles" (Coan, 2013, p. 54). Esse recorte é evidente e talvez o mais influente em Skinner no auge de seu historicismo ${ }^{17}$.

O contextualismo linguístico de 1969 pode ser entendido como a "elaboração mais sistemática do encontro da filosofia da história de Collingwood com o aparelho analítico da filosofia da linguagem ordinária" (Silva, 2010, p. 303). Em termos práticos, isso significou a reconstrução do objeto do campo: do conteúdo abstrato de doutrinas para a performance de um ator intencionado e historicamente situado.

16 Skinner chega a afirmar, por exemplo, que "já foi classicamente demonstrado [...] por J. L. Austin, que acompreensão de enunciados pressupõe um entendimento não apenas do sentido de uma dada declaração, mas também do que Austin chamou de sua intencionada força ilocucionária” (Skinner, 1969, p. 45, tradução própria). No original: "it has been classically demonstrated [...]by J. L. Austin, that the understanding of statements presupposes a grasp not merely of themeaning of the given utterance, but also of what Austin labelled its intended illocutionary force."

17 Em talvez sua manifestação mais forte: "Há também a outra implicação de que - revivendo amaneira de colocar a questão de Collingwood - simplesmente não existem questões perenes nafilosofia: existem apenas respostas individuais para questões individuais, com tantas diferentesrespostas quanto há diferentes perguntas, e tantas diferentes perguntas quanto há diferentesquestionadores." (SKINNER, 1969, p. 50). No original: "There is also the further implicationthat - to revive Collingwood's way of putting it - there simply are no perennial problems in philosophy: there are only individual answers to individual questions, with as many differentanswers as there are questions, and as many different questions as there are questioners". Como afirma Isadora Coan, a seleção mesmo de obras colingwoodianas manuseadas por Skinner (The Idea of history, An essay on metaphysicse Na autobiography) já é indicativa desse caráter, pois é considerada "por alguns comentadores da obra de Collingwood como constituintes de uma fase historicista radical" (2013, p. 64). 
Um texto deve ser compreendido em termos daquilo que o seu autor estava fazendo ao escrevê-lo. O modo de alcançar essa compreensão é o "esclarecimento do uso que se fazia das palavras em outras etapas históricas"18 (Rodriguez, 2013, p. 272, tradução própria), é “delinear toda a rede de comunicações que poderia ter sido convencionalmente performada na dada ocasião pela enunciação do enunciado, e, depois, traçar as relações entre esse enunciado e seu mais amplo contexto linguístico"19 (Skinner, 1969, p. 49, tradução própria). O dilema da transposição é solúvel porque todo ato de comunicação bem-sucedido compreende dentro de si a noção de signos linguísticos socialmente partilhados; na aspiração de se produzir um efeito ao leitor, as intenções de um texto devem ser publicamente apreensíveis - e o único caminho para esse fim é se apropriar de um conjunto de normas de linguagem compreensíveis pelo interlocutor.

Enquanto os movimentos realizados por Geertz e Skinner podem parecer diferentes, o framework proposto por ambos é semelhante. O que ajuda explicar suas idiossincrasias são os diferentes objetos, debates e áreas de estudo de ambos. O conceito de cultura de Geertz aparentemente diminui a centralidade da ação por ser essencialmente simbólico, enquanto o esforço de Skinner é justamente ressaltar o caráter de ação dos atos linguísticos. Entretanto, nem Geertz pressupõe cultura sem ação, nem Skinner pressupõe ação sem contexto simbólico. Os concorrentes contemporâneos de suas respectivas áreas do conhecimento (o estrutural funcionalismo no caso da antropologia, e o textualismo da filosofia política no caso da história das ideias) é que os levaram a acentuar elementos específicos de suas metodologias. Percebe-se, porém, uma comum concepção ontológica do mundo social (weberiana) onde agentes intencionados referem-se a uma teia de significados por eles mesmos tecidos ao agir: enquanto Geertz preocupa-se em apreender essa teia de significados (a cultura) através da ação de agentes específicos, Skinner preocupa-se em entender a ação de agentes específicos recorrendo a essa teia de significados às quais ele se referia ao escrever o que escreveu.

$O$ registro fortemente intencionalista de Quentin Skinner ainda merece atenção pois revela outras relações com o interpretativismo. Ao se contrapor aos contextualistas sociologizantes, o britânico denunciaria que o problema de suas abordagens "repousaria sobre a confusão entre dois procedimentos intelectuais inteiramente distintos: a determinação causal de uma ideia e a sua compreensão

18 No original: "esclarecimiento del uso que se hacía de las palabras en otras etapas históricas".

19 No original: "to delineate the whole range of communications which could have been conventionally performed on the given occasion by the utterance of the given utterance, and, next, to trace the relations between the given utterance and this wider linguistic context". 
propriamente dita” (Silva, 2010, p. 305). Para Skinner, compreender uma ação é algo mais do que entender condições causais antecedentes a esta ação, é também entender o ponto da ação para o agente que a performou. Toda ação performada pressupõe condicionantes causais, uma intenção de realização e uma intenção ao realizar. Pensando nesses termos, a história das ideias, "a compreensão de uma ideia enquanto ação linguística significa algo mais do que sua explicação causal" (Silva, 2010, p. 305), significa a captura da intencionalidade do autor ao agir como agiu - do intelectual ao escrever como escreveu. Por isso, compreender um texto vai além de analisar o significado de um determinado enunciado em sua composição semântica, gramatical; também vai além de estudar o contexto social onde ele foi escrito e explicar como este influenciou sua escrita; é necessário um empreendimento linguístico de reconstrução das diversas comunicações que este enunciado poderia performar em sua dada ocasião e de traçamento de relações deste enunciado com seu mais amplo contexto linguístico. Dessa forma, pode o pesquisador capturar a dimensão ilocucionária do ato de fala. Somente esse processo esgota o objeto: "mesmo que o estudo do contexto social de textos possa servir para explicá-los, isso não significaria o mesmo que dar meios de compreendê-los" ${ }^{\circ o}$ (Skinner, 1969, p. 46, grifos no original, tradução própria).

Como consequência, não pode ser o suficiente estudar somente o que o enunciado significou, tampouco o que o seu contexto pode supostamente demonstrar sobre o que ele deve ter significado. O ponto mais central que precisa ser entendido de qualquer enunciado é como o que foi dito foi significado, e, portanto, que relações podem existir entre vários enunciados diferentes mesmo dentro do mesmo contexto geral. ${ }^{21}$ (Skinner, 1969, p. 47, tradução própria).

É preciso enfatizar, então, que se trata de um argumento sobre insuficiência: faz parte da preocupação metodológica skinneriana dar atenção ao contexto social de um ator-intelectual, e é para ele uma asserção ontológica verdadeira a de que nesse contexto encontram-se condicionantes causais para ideias e ideólogos. Esse posicionamento, posto em contraste contra outros interpretativistas, revela um

20 No original: "even if the study of the social context of texts could serve to explain them, this would not amount to the same as providing the means to understand them".

21 No original: "It cannot in consequence be enough to study either what the statement meant, or even what its context may be alleged to show about what it must have meant. The further point which must still be grasped for any given statement is how what was said was meant, and thus what relations there may have been between various different statements even within the same general context." 
distanciamento das colocações mais radicais contra pressupostos caros do raciocínio científico como a causalidade. Afinal, o britânico em 1969 acreditava estar propondo um método historiográfico de análise capaz de alcançar a compreensão final de um texto histórico - o que, assim como para Geertz, lhe traria uma série de críticas sobre esgotamento de contexto e critérios de verificação.

\section{CONSIDERAÇÕES FINAIS}

A ligação entre Clifford Geertz e Quentin Skinner dificilmente é uma novidade: ambos inclusivejá colaboraram em projetos e dividiram departamento no Instituto de Estudos Avançados de Princeton. Em 2001, por exemplo, participaram ambos da coletânea Schools of Thought: Twenty-five Years of Interpretive Social Science, organizada por Joan Scott e Debra Keates. Este artigo buscou ressaltar o caráter dessa relação em seus corpos teóricos como pensados nas suas iniciais e ousadas intervenções nas ciências humanas nos anos 1960. Mesmo separados em áreas de conhecimento diferentes, há muito mais semelhanças do que distanciamentos entre os dois intelectuais. Juntos eles se empenharam em combater pressupostos positivistas hegemônicos, resgatando lições de teóricos compreensivos do século XIX e as reformulando com as contribuições da filosofia da linguagem; propuseram um projeto intencionalista, contextualista e, ainda mais importante, interpretativista de análise de seus respectivos objetos, afastando-se, porém, de outros interpretativistas em pontos sensíveis sobre o conhecimento científico e a relação entre verdade e método.

Mais de 40 anos depois de suas publicações impactantes no começo de suas carreiras, ambos continuam sendo enormemente influentes na antropologia e na história das ideias e motivam ainda entusiastas e críticos - sinal incontornável da importância de voltar aos tempos efervescentes do início da "revolução" da virada interpretativa.

\section{REFERÊNCIAS BIBLIOGRÁFICAS}

COAN, Isadora Cristina de Melo (2010). Interpretando uma alternativa: Considerações sobre a virada interpretativa nas ciências sociais entre as décadas de 1960 e 1970. Trabalho de Conclusão de Curso (Graduação) em Ciências Sociais. Florianópolis: Universidade Federal de Santa Catarina. Disponível em <https://repositorio.ufsc.br/ handle/123456789/125755>. $80 \mathrm{p}$.

COAN, Isadora Cristina de Melo (2013). As bases filosóficas da metodologia de Quentin Skinner para a história intelectual. Dissertação (Mestrado) em Sociologia Política. Florianópolis: Centro de Filosofia e Ciências Humanas da Universidade Federal de 
Santa Catarina. Disponível em <http://bdtd.ibict.br/vufind/Record/UFSC_782a5a ecc36de8a6837a6e8foea5b58d/Details $>$.

COSTA, Cláudio (2007). Filosofia da Linguagem. Rio de Janeiro: Jorge Zahar.

GADAMER, Hans-Georg (1967). "A universalidade do problema hermenêutico. Retórica, hermenêutica e crítica da ideologia - comentários metacríticos a Verdade e Método 1”. ln: GADAMER, Hans-Georg.Verdade e Método II: Complementos e índice. Petrópolis: Vozes, 2002.

GEERTZ, Clifford (1979). "From the native's point of view: on the nature of anthropological understanding (1976)". In: RABINOW, Paul; SULLIVAN, William (eds.). Interpretive social science: a reader. Berkeley: University of California Press.

GEERTZ, Clifford (1980). The refiguration of social thought. American Scholar, v. 49, n. 2, p. 165-79.

GEERTZ, Clifford (2008). A interpretação das culturas.Rio de Janeiro: LTC.

GIBBONS, Michael (2006). Hermeneutics, political inquiry, and practical reason: an evolving challenge to political science. American Political Science Review, v. 100, n. 4. JASMIN, Marcelo Gantus (2005). História dos conceitos e teoria política e social: referências preliminares. Revista Brasileira de Ciências Sociais, v. 20, n. 57, p. 27-38. LEEDS-HURWITZ, Wendy (2015). “Thick description”. In: TRACY, Karen; ILIE, Cornelia; SANDEL, Todd (orgs.). The International Encyclopedia of Language and Social Interaction, First Edition. Nova Jersey: John Wiley \& Sons.

LOPES, Marcos Antônio (2011). Aspectos teóricos do pensamento histórico de Quentin Skinner. Revista Kriterion, v. 52, n. 123, p. 177-95.

LOSSO, Tiago (2011). A crítica de Charles Taylor ao naturalismo na ciência política. Revista de Sociologia e Política. Curitiba, v. 19, n. 39, p. 91-10.1

RABINOW, Paul; SULLIVAN, William M (1979). "The interpretative turn: emergence of an approach" ln: RABINOW, Paul; SULLIVAN, William M (eds.). Interpretive social science: a reader. Berkeley: University of California Press.

RODRIGUEZ, Cristian Uriel Solís (2013). La relación contexto-sujeto en Quentin Skinner. Región y sociedad. Obregón, ano xxv, n. 56, p. 269-97.

SHANKMAN, Paul (1984). The Thick and the Thin: On the Interpretive Theoretical Program of Clifford Geertz. Current Anthropology, v. 25, n. 3, p. 261-80.

SILVA, Ricardo (2010). O Contextualismo Linguístico na História do Pensamento Político: Quentin Skinner e o Debate Metodológico Contemporâneo. Revista DADOS - Revista de Ciências Sociais, v. 53, n. 2, p. 299-335.

SKINNER, Quentin (1969). Meaning and Understanding in the History of Ideas. History and Theory, v. 8, n. 1, p. 3-53.

Recebido: 21/05/2020 | Aprovado: 07/04/2021 